\title{
Assessment of Various Self Healing Materials to Enhance the Durability of Concrete Structures
}

\author{
Chereddy Sonali Sri Durga*, Nerella Ruben \\ Department of Civil Engineering, Vignan's Foundation for Science, Technology \& Research, Vadlamudi, Andhra Pradesh, \\ India
}

Corresponding Author Email: chereddysony@gmail.com

https://doi.org/10.18280/acsm.430202

Received: 16 January 2019

Accepted: 26 March 2019

\section{Keywords:}

bio-concrete, concrete properties, cracking, eco-friendly, mechanisms, self healing

\begin{abstract}
Concrete is a human-made construction material which is assembled by cement, coarse aggregate, fine aggregate and water. Concrete is susceptible to cracking, as small cracks have no effect but large cracks cause disintegration of concrete structures. These cracks will allow chemicals and gases to enter disturbing the lifespan of structures. Reconstruction and maintenance of concrete structures are most difficult and expensive because of labour cost, energy and cost required to produce cement are high. Self healing materials are used to heal the cracks of concrete structures. These materials are eco-friendly can heal the cracks by producing precipitated crystals like calcium carbonate. The inner portion of cracks can also be sealed by these self healing materials. The main aim of this paper is to represent the mechanisms of various materials, i.e. biological agent, chemical agent, supplementary cementitious materials, crystalline admixtures and super absorbent polymers used for self healing are detailed. The way of application of self healing material to concrete is briefed. Through this study the rate of self healing, mechanical properties and durability properties of concrete are computed. The micro structural behaviour of hydrated products is analyzed.
\end{abstract}

\section{INTRODUCTION}

Concrete is one of the multifaceted construction material used widely in the world. It is a material which comprises of cement paste and aggregates. Durability, strength, adaptability, fire resistance, affordability, thermal mass, availability and simple formation are some of the properties of concrete. Concrete is strong in compression and weak in tension. To strengthen the tensile zone of concrete, it is reinforced with steel bars. No matter what is the design and how the structure is constructed, concrete is prone to cracking which influences the durability of concrete structures.

Cracks are formed in concrete due to the temperature differences, excess water in the mix, shrinkage, fatigue loads and settlement of structures. The durability of concrete is impaired by the cracks since they provide an accessible path for the transportation of gases and liquids to enter into concrete. If the micro cracks grow and reach the reinforcement, not only the concrete itself may be attacked but also the reinforcement will be corroded. Therefore it is essential to control the crack width as soon as possible. Hence the repair and maintenance of concrete structures are complicated and expensive, this drawback focus on the development of self healing concrete.

Self healing materials are the artificially made substances which heal the cracks on the surface of concrete structures. This motivation comes from the biological systems which can heal after being wounded. Healing is of two types, i.e. autogenous healing and autonomous healing. Autogenous healing is the one which does not require an external agent for the healing of cracks, heals by the chemical reactions of cementitious materials. Autonomous healing is the one which consists of external agents such as biological agents like bacteria, chemical agents like calcium lactate, supplementary cementitious materials like fly ash to heal the cracks on the surface of concrete structures. The mechanisms of various self healing materials are shown in Figure 1.

This paper reviews a path of dealing with cracks on the surface of concrete structures. The mechanisms of various self healing materials used for healing the cracks are discussed. The tests used to evaluate the mechanical and durability properties are examined. The micro structural behaviour of healing products is explained.

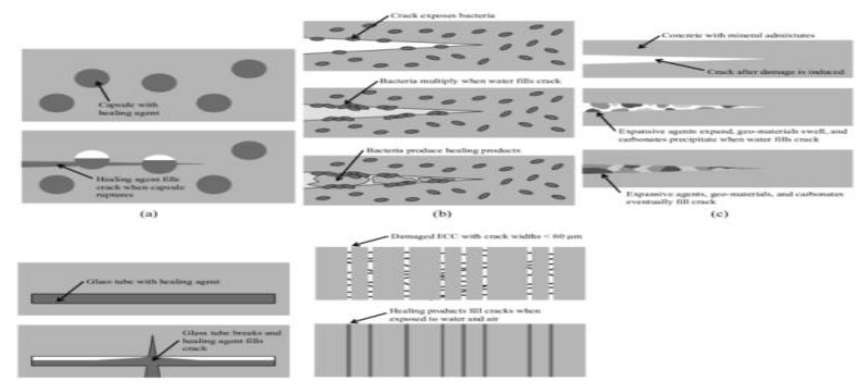

Figure 1. Self healing process [1]

\section{MECHANISMS OF VARIOUS SELF HEALING MATERIALS}

\subsection{Biological agent}

A biological agent can be defined as a substance that is a naturally available living organism that heals the cracks on the surface of the concrete. The biological agent can be classified into 3 types, i.e. bacteria, virus and fungi. 
Jing $\mathrm{Xu}$ et al. [2] have prepared specimens using sporosarcina pasteurii bacteria and ceramsite particles. Mechanical properties and self healing rate were evaluated. The ceramsite particles were used as a protective carrier for bacteria which were loaded with only nutrients, only spores, both spores and nutrients. To increase the load carrying capacity of ceramsite particles, the preliminary treatments such as alkali erosion and sintering are performed. The ceramsite particles are treated with a $\mathrm{NaOH}$ solution and with a sintering temperature ranging from $400{ }^{\circ} \mathrm{C}$ to $1000{ }^{\circ} \mathrm{C}$. The increase in weight ratio with respect to different $\mathrm{NaOH}$ concentrations is shown in Figure 2. The maximum heating temperature is $750{ }^{\circ} \mathrm{C}$. The increase in weight ratio with different sintering temperatures is shown in Figure 3. There is an increase of $20 \%$ compressive strength and the water absorption decreases to $30 \%$. The maximum crack width healed was $0.3 \mathrm{~mm}$ and the percentage of self healing rate is $86 \%$.

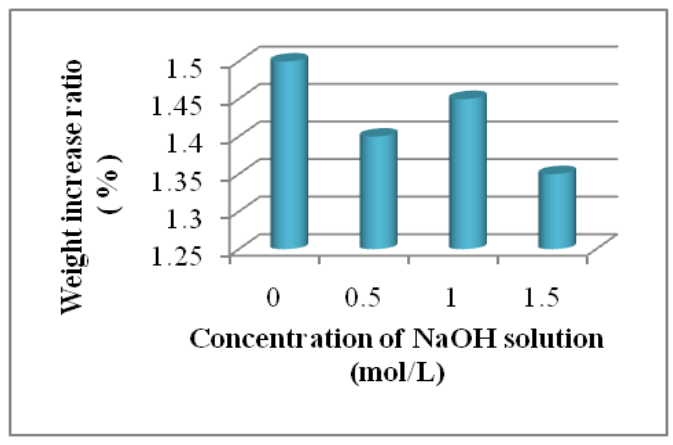

Figure 2. Loading content by alkali erosion at different concentrations of $\mathrm{NaOH}$ solution [2]

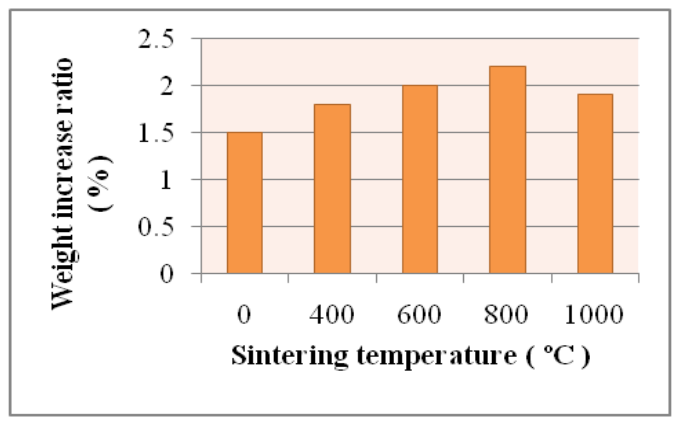

Figure 3. Loading content by heat treatment with different sintering temperatures [2]

\subsection{Chemical agent}

A chemical agent can be defined as the agent that produces chemical reactions when applied or mixed to other substance by contact with air, water and soil. The chemical agents can be in various forms, i.e. solid, liquid and gas. The chemical agents can be used as a curing solution or can be mixed with concrete by encapsulation process to heal the cracks on the surface of the concrete. The capsules encapsulated can be analyzed by experimental work and software also.

Jean Ducasse-Lapeyrusse et al. [3] has cast the disk-shaped mortar specimens of $150 \mathrm{~mm}$ diameter and $50 \mathrm{~mm}$ thick. A central hole of $55 \mathrm{~mm}$ diameter is used to insert the expansive core which is used to generate realistic cracks of controlled dimensions. Small $(<150 \mathrm{~mm})$ and large $(>150 \mathrm{~mm})$ cracks are formed after 28 days of curing. Instantaneously after cracking, the samples are immersed in calcium lactate $(79 \mathrm{~g} / \mathrm{L})$, calcium gluconate $(20 \mathrm{~g} / \mathrm{L})$ and urea $(10 \mathrm{~g} / \mathrm{L})$ solutions for healing. Airflow measurements are used to evaluate the effective crack width opening at a period of 1, 3, 6 and 11 months. The samples immersed in calcium gluconate and calcium lactate solutions show more rate of healing on the large cracks, as there is no effect on the fresh crack samples immersed in the urea solution because urea itself can't provide calcium for the healing of cracks.

Luthfi M.Mauludin et al. [4] has developed a model with mortar, aggregate particles, capsule core, capsule shell and bond between them to analyze the $2 \mathrm{D}$ fracture process utilizing finite element package ABAQUS. A capsule made up of polymethyl methacrylate of $2 \mathrm{~mm}$ diameter with a shell thickness of diameter/27 was used. The volume fraction of capsules varies from $1.57 \%$ to $9.42 \%$. The models have meshed with various sizes of $0.5 \mathrm{~mm}, 0.75 \mathrm{~mm}, 1 \mathrm{~mm}$. As the volume fraction of the capsule increases, the dissipating energy increases but there is a decrease in tensile strength. It was reported that there is no effect on strength when the volume fraction of capsules is less than $2 \%$.

Maria Araujo et al. [5] have prepared samples with polymethyl methacrylate and glass capsules. The polymethyl methacrylate capsules are made with an outer diameter $6.5 \mathrm{~mm}$, wall thickness $0.7 \mathrm{~mm}$ and length $50 \mathrm{~mm}$ whereas glass capsules are made of outer diameter $5 \mathrm{~mm}$, wall thickness $0.8 \mathrm{~mm}$ and length $50 \mathrm{~mm}$. The beam samples are subjected to cracking by 3 points bending test after 14 days of curing. The cracks widths measured for 6 different cracks in glass capsules, PMMA capsules and control concrete samples are shown in Figure 4. X-ray $(\mu \mathrm{CT})$ was used to represent the circulation of capsules in the concrete matrix and leakage of liquid after crack formation. The glass capsules show more healing rate because of their extra distribution compared to PMMA capsules.

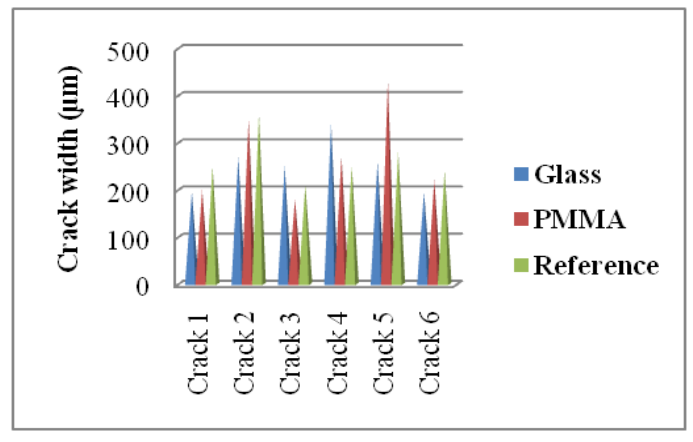

Figure 4. Average crack width measured at the crack mouth for each beam [5]

Philip Van den Heede et al. [6] has prepared cylindrical samples using borosilicate glass capsules with a four polymer based healing agents. The glass capsule is made of outer diameter $3.35 \mathrm{~mm}$, inner diameter $3 \mathrm{~mm}$ and length $35 \mathrm{~mm}$. The four polymer based healing agents are high viscosity polyurethane precursor, low viscosity polyurethane precursor, low viscosity polyurethane precursor with accelerator and benzoyl peroxide, two component acrylate end-capped precursor with cross linker. The cylindrical samples are subjected to cracking and are sprayed with $0.1 \mathrm{~mol} / \mathrm{L}$ silver nitrate solution to assess the chloride ingress. By the chloride migration test, the self healing efficiency can be estimated. It was concluded that a low viscosity polyurethane precursor 
shows a $100 \%$ self healing efficiency with a minor possibility of early setting inside the capsule.

\subsection{Biological agent and chemical agent}

Mostafa Seifan et al. [7] has cast cylindrical and beam specimens with Bacillus sphaericus, Bacillus licheniformis and iron oxide nanoparticles. The cylindrical specimens are cured for 3, 7 and 28 days for estimating the compressive strength. The beam samples are cured for 3, 7, 14 and 28 days for measuring the drying shrinkage. The microscopic behaviour of healing products can be checked by energydispersive X-ray spectroscopy and X-ray diffraction. The compressive strength values for bio based and reference concrete specimens are shown in Figure 5. There is an increase in compressive strength and a decrease in the higher rate of shrinkage compared to control specimens.

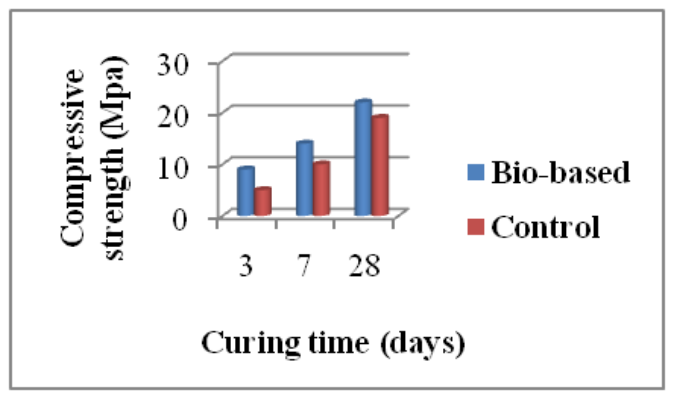

Figure 5. Comparison of compressive strength of the control and the bio-based concrete samples for 3, 7 and 28 days [7]

Carlos C.Insaurralde et al. [8] have cast samples using bacteria and shape memory alloys. A concrete matrix which consists of bacteria and shape memory alloys can be indicated as a Bacterial and Memory Material Concrete. Nondestructive tests such as ultrasonic pulse velocity and electric resistance are used to calculate the self healing rate. From the ultrasonic pulse velocity measurements, it was seen that the quality of control samples is more compared to samples prepared with bacteria and shape memory alloys. The electric resistance is less in the control samples compared with samples made of bacteria and shape memory alloys.

\subsection{Supplementary cementitious materials}

Supplementary cementitious materials are the one which is having vast amounts of aluminous and siliceous contents but having little or no cementitious value. These materials are in fine form when mixed with water they chemically react with calcium hydroxide and form compounds carrying cementitious properties at average temperatures. Supplementary cementitious materials are also known as Mineral admixtures or Pozzolanic materials. These materials are used to increase strength and durability, reduce water demand, lower the heat of hydration and reduce permeability in the concrete matrix.

Nanayakkara et al. [9] has prepared rectangular specimens embedded with steel bars of $6 \mathrm{~mm}$ diameter using ordinary Portland cement and Portland pozzolana cement with a limestone percentage of $5 \%$ and $12 \%$. The samples are cured for 28 days and subjected to cracking using compression load. Steel straps are provided around the samples to limit the crack width. A constant head of water supply is allowed on the cracked specimens for healing. The crack width was measured continuously, as there is an accelerated rate of healing during the earlier 2 days of water exposure. The equivalent crack width was calculated with formulae by using the flow rate. There is a variation in the measured crack width and equivalent crack width because of unevenness inside the crack.

Nele De Belie et al. [10] stated that the usage of Supplementary cementitious materials results in the decrease in cement content in preparation of concrete. Material costs and atmosphere destruction decreases. These materials require less energy for production and release less amount of carbon dioxide into the environment. By adding these materials to the concrete matrix, there is a continuous ongoing hydration process and the hydration products such as $\mathrm{CSH}$, ettringite, hydrogarnet and hydrotalcite are formed. For the continuous hydration process, these materials require a minimum amount of calcium hydroxide content. The rate of healing is slow; to accelerate the healing process several ionic solutions are used.

\subsection{Crystalline admixtures}

Nele De Belie et al. [10] Crystalline admixtures are the one which is made of active chemicals react chemically with water and produces hydration products to improve the density of $\mathrm{CSH}$ gel. Crystalline admixtures are also known as permeability-reducing admixtures. These admixtures can resist hydrostatic conditions. Tricalcium silicate is the component of concrete that reacts with crystalline admixtures. There is an increase in mechanical properties when $3 \%, 5 \%$, $7 \%$ of crystalline admixture are replaced by weight of cement and reacts with water.

\subsection{Super absorbent polymers}

Super absorbent polymers are the water absorbing polymers consists of hydrogels and cross linkers. It is a polymer which is nonpolluting, nontoxic, harmless and possesses water holding capability and proper water absorption. Super absorbent polymers are of two types, i.e. natural and synthetic. Nele De Belie et al. [10] has mentioned that superabsorbent polymers can absorb water more than its own weight and convert into an ordinary gel within a short time. When cracks are formed in the concrete matrix, the superabsorbent polymers react with the environment and swell. The swelling capability depends on the monomer and density of cross linker. These polymers are multifunctional, acts as an internal curing agent with a low water-cement ratio to reduce shrinkage during hardening and increases freeze-thaw resistance.

\section{TEST METHODS}

\subsection{Mechanical properties of concrete}

The performance of concrete can be assessed by the mechanical properties such as compressive strength, split tensile strength, flexural strength, creep, shrinkage, modulus of elasticity and Poisson's ratio. Compressive strength is an essential property of concrete as concrete is strong in compression and weak in tension. The effects of various selfhealing materials on the mechanical properties of concrete as listed here.

\author{
3.1.1 Compressive strength test \\ Compressive strength can be defined as the capability of the
}


material to resist loads against failure. Jing $\mathrm{Xu}$ et al. [5] has prepared cube samples of $50 \times 50 \times 50 \mathrm{~mm}$ using sporosarcina pasteurii bacteria and ceramsite particles which were loaded with only nutrients, only spores and both spores and nutrients. The samples are cracked by the compressive load and strength was estimated. After 28 days of healing, again the samples are tested for compressive strength. The regain ratio can be calculated by the compressive strength before healing and after healing. The compressive strength values of the control samples and specimens with ceramsite particles are shown in Figure 6 . There is an increase in $20 \%$ compressive strength for the samples casted using both spores and nutrients compared to the normal concrete samples.

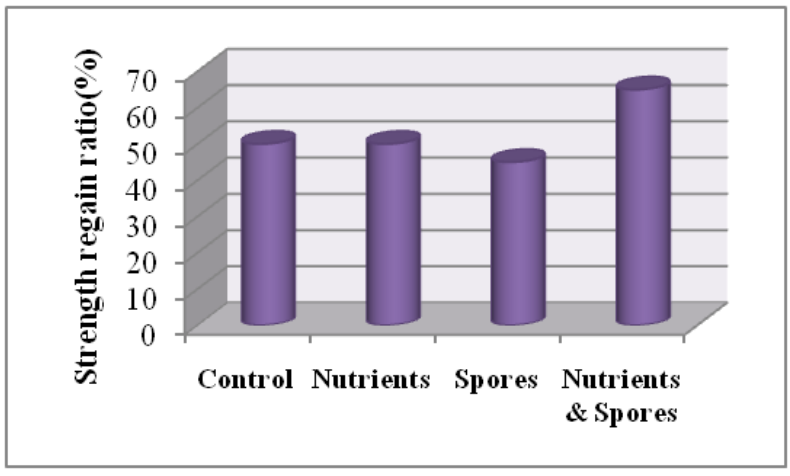

Figure 6. The regain ratio of the compressive strength by self healing [5]

\subsubsection{Bending strength test}

Bending strength is also known as flexural strength of concrete. It is defined as the ability of a material to withstand load against failure in bending. Daquan Sun Bin Li et al. [11] has prepared beam specimens using $3 \% \mathrm{wt}$ of melamine urea formaldehyde microcapsules containing rejuvenator and asphalt. A four-point bending test was carried on the beam specimens for cracking. The specimens are cured for healing. The healing performance of the asphalt concrete depends on the flow velocity of the molecules. It was reported that the addition of $3 \%$ wt of melamine urea formaldehyde microcapsules increases the fatigue life of asphalt concrete.

\subsubsection{Drying shrinkage test}

The change in volume of concrete is termed as shrinkage. This volume change is due to loss of water which increases tensile stresses and causes cracking. They are various types of shrinkage, i.e. drying shrinkage, carbonation shrinkage and plastic shrinkage.

Mostafa seifan et al. [4] has cast specimens with dimensions of $75 \times 75 \times 285 \mathrm{~mm}$ with Bacillus sphaericus, Bacillus licheniformis and iron oxide nanoparticles. The specimens are placed in the lime-saturated solution for $30 \mathrm{~min}$ and length was measured. Again the length was measured after the specimens are placed in the lime-saturated solution for 28 days of curing and allowed for shrinkage. The readings of shrinkage were taken at 3, 7, 14, 28, 56 and 108 days. The results show that there is a high free shrinkage for bio-specimens compared to control specimens.

\subsection{Durability properties of concrete}

The durability of concrete is termed as the capacity of a material to withstand environmental parameters such as relative humidity, precipitation, chemical attack and abrasion.
Some of the durability tests are carbonation, water permeability, sulphate attack, acid attack, rapid chloride penetration, sorptivity, accelerated corrosion and alkali-silica reaction. The effects of different self-healing materials on the durability properties of concrete as follows

Maria Araujo et al. [2] have prepared beam samples with glass and polymethyl methacrylate capsules. The samples are subjected to cracking. To find the chloride ingress, the 2 core samples of $150 \mathrm{~mm}$ diameter with cracks are extracted from the beams. The samples are immersed in $3 \%$ wt of $\mathrm{NaCl}$ solution for $24 \mathrm{hrs}$ and dried for 6 days. These wet-dry cycles were continued for 42 days. Except on the top surface, all the surfaces are covered with water proof aluminum foils so that the top surface is subjected to chloride ingress. It was concluded that both the samples with glass and polymethyl methacrylate capsules offers good resistance against chloride ingress.

\subsection{Microstructure observation}

The microscopic study of concrete can be done by various analysis like scanning electron microscopy, X-ray diffraction, texture element microscopy and energy dispersive X-ray spectroscopy. The microstructure behavior of discrete materials is described here

Mostafa seifan et al. [4] has cast samples using Bacillus sphaericus, Bacillus licheniformis and iron oxide nanoparticles. The samples are cracked using compressive loading and permit for healing. The micro morphology of healing products can be assessed using X-ray diffraction and energy dispersive X-ray spectroscopy. EDX and XRD analysis confirmed that the precipitated crystals are calcium carbonate. EDX analysis says that the calcium, oxygen and carbon atoms are the components present in the precipitated crystals.

\section{CONCLUSIONS}

Self healing materials are crack resistant, eco-friendly, increase the lifespan of concrete structures, reduce cement production, labour costs and maintenance costs of structures. These materials produce healing products such as calcium carbonate and heal the cracks on the surface of the concrete. By using self healing materials, there is an increase of $20 \%$ compressive strength, fatigue life of asphalt concrete has doubled, offers good resistance against chloride ingress, water absorption decreases to $30 \%$ and the healing ratio of cracks reaches to $86 \%$. By studying the micro structural behaviour, it was seen that the precipitated crystals are calcium carbonate contains oxygen atoms, calcium atoms and carbon atoms. Some issues have to resolve, i.e. the numerical solution to the self healing process, the active period of bacteria, low healing efficiency and additional costs.

\section{REFERENCES}

[1] Li, V.C., Herbert, E. (2012). Robust self-healing concrete for sustainable infrastructure. Journal of Advanced Concrete Technology, 10(6): 207-218. https://doi.org/10.3151/jact.10.207

[2] Xu, J., Wang, X., Zuo, J., Liu, X. (2018). Self-healing of concrete cracks by ceramsite-loaded microorganisms. Advances in Materials Science and Engineering, 2018: 
1-8. https://doi.org/10.1155/2018/5153041

[3] Ducasse-Lapeyrusse, J., Gagné, R., Lors, C., Damidot, D. (2017). Effect of calcium gluconate, calcium lactate, and urea on the kinetics of self-healing in mortars. Construction and Building Materials, 157: 489-497. https://doi.org/10.1016/j.conbuildmat.2017.09.115

[4] Mauludin, L.M., Zhuang, X., Rabczuk, T. (2018). Computational modeling of fracture in encapsulationbased self-healing concrete using cohesive elements. Composite $\quad$ Structures, 196: 63-75. https://doi.org/10.1016/j.compstruct.2018.04.066

[5] Araújo, M., Chatrabhuti, S., Gurdebeke, S., Alderete, N., Tittelboom, K.V., Raquez, J., Gruyaert, E. (2018). Poly(methyl methacrylate) capsules as an alternative to the "'proof-of-concept'" glass capsules used in selfhealing concrete. Cement and Concrete Composites, 89: 260-271.

https://doi.org/10.1016/j.cemconcomp.2018.02.015

[6] Heede, P.V., Belleghem, B.V., Araújo, M.A., Feiteira, J., Belie, N.D. (2018). Screening of Different Encapsulated Polymer-Based Healing Agents for Chloride Exposed Self-Healing Concrete Using Chloride Migration Tests. Key Engineering Materials, 761: 152-158. https://doi.org/10.4028/www.Scientific.net/kem.761.15 2
[7] Seifan, M., Sarmah, A.K., Samani, A.K., Ebrahiminezhad, A., Ghasemi, Y., Berenjian, A. (2018). Mechanical properties of bio self-healing concrete containing immobilized bacteria with iron oxide nanoparticles. Applied Microbiology and Biotechnology, 102(10): 4489-4498. https://doi.org/10.1007/s00253018-8913-9

[8] Insaurralde, C.C., Rahman, P.K., Ramegowda, M., Vemury, C.M. (2016). Follow-up methods for autonomic repairing process. 2016 IEEE International Conference on Systems, Man, and Cybernetics(SMC). https://doi.org/10.1109/smc.2016. 7844997

[9] Nanayakkara, S.M., Elakneshwaran, T. (2005). Selfhealing of cracks in concrete with portland limestone cement. Cement Combinations for Durable Concrete, 675-683. https://doi.org/10.1680/ccfdc.34013.0073

[10] Belie, N.D., Gruyaert, E., Al-Tabbaa, A., Antonaci, P., Baera, C., Bajare, D., Jonkers, H.M. (2018). A review of self-healing concrete for damage management of structures. Advanced Materials Interfaces, 5(17): 1800074. https://doi.org/10.1002/admi.201800074

[11] Sun, D., Li, B., Ye, F., Zhu, X., Lu, T., Tian, Y. (2018). Fatigue behavior of microcapsule-induced self-healing asphalt concrete. Journal of Cleaner Production, 188: 466-476. https://doi.org/10.1016/j.jclepro . 2018.03.281 